\title{
The intricate role of mast cell proteases and the annexin A1-FPR1 system in abdominal wall endometriosis
}

\author{
Rubens Paula Jr. • Antonio H. Oliani • \\ Denise C. M. Vaz-Oliani · Solange C. G. P. D’Ávila • \\ Sonia M. Oliani · Cristiane D. Gil
}

Received: 6 August 2014/Accepted: 3 September 2014/Published online: 9 September 2014

(C) Springer Science+Business Media Dordrecht 2014

\begin{abstract}
Endometriosis is a continuous and progressive disease with a poorly understood aetiology, pathophysiology and natural history. This study evaluated the histological differences between eutopic and ectopic endometria (abdominal wall endometriosis) and the expression of mast cell proteases (tryptase and chymase), annexin A1 (ANXA1) and formyl peptide receptor 1 (FPR1). Ectopic endometrium from 18 women with abdominal wall endometriosis and eutopic endometrium from 10 women without endometriosis were obtained. The endometrial samples were analysed by histopathology, immunohistochemistry and ultrastructural immunogold labeling to determine mast cell heterogeneity (tryptase and chymase positive cells) and the expression levels of ANXA1 and FPR1. Histopathological analysis of the endometriotic lesions showed a glandular pattern of mixed differentiation and an undifferentiated morphology with a significant influx of inflammatory cells and a change in mast cell heterogeneity, as evidenced by a significant increase in the number of chymase-positive cells and endogenous chymase expression. The undifferentiated glandular pattern of
\end{abstract}

R. Paula Jr. · S. M. Oliani

Laboratório de Imunomorfologia, Departamento de Biologia, Universidade Estadual Paulista (UNESP), São José do Rio Preto, São Paulo 15054-000, Brazil

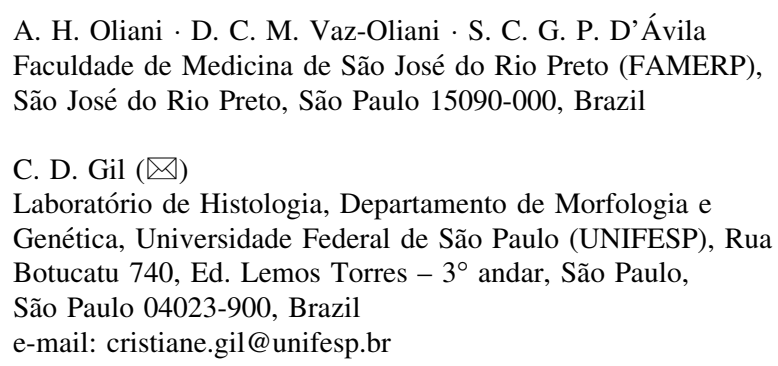

endometriotic lesions was positively associated with a marked increase and co-localization of ANXA1 and FPR1 in the epithelial cells. In conclusion, the co-upregulated expression of mast cell chymase and ANXA1-FPR1 system in ectopic endometrium suggests their involvement in the development of endometriotic lesions.

Keywords Chymase - Endometrioma .

Immunohistochemistry · Inflammation · Lipocortin-1 .

Transmission electron microscopy

\section{Introduction}

Endometriosis is a chronic inflammatory and multifactorial disease and represents a public health problem that affects $10-20 \%$ of women in reproductive age. This disease often causes chronic pain and infertility (Podgaec et al. 2007; Burney 2013). Endometriosis is characterised by the presence of endometrial-like tissue outside the uterine cavity. The endometrial implants are most commonly found in the pelvic cavity but can also be found in the ovaries, rectovaginal septum and occasionally in the pericardium, pleura, liver, kidney, bladder, and brain (Giudice and Kao 2004; Jiang and Wu 2012). In some patients, these implants can proliferate in the abdominal wall or ovaries and develop into a benign tumour called endometrioma (Accetta et al. 2011; Ozel et al. 2012; Ding and Zhu 2013).

The relationship between mast cells and endometriosis has been reported in the literature. Increased numbers of these cells have been found in the ectopic lesions (Konno et al. 2003; Fujiwara et al. 2004; Kempuraj et al. 2004; Sugamata et al. 2005; Menzies et al. 2011). One of these studies revealed high numbers of activated mast cells in endometriosis sites that were strongly positive for 
corticotrophin-releasing hormone and urocortin both of which can activate mast cells and contribute to the fibrosis and inflammation in endometriosis (Kempuraj et al. 2004).

In addition, the inflammatory response is controlled by anti-inflammatory mediators that maintain the homeostasis of the immune response and prevent tissue damage. Among these mediators we highlight annexin A1 (ANXA1), a $37 \mathrm{kDa}$ protein with potent anti-inflammatory functions, expressed in different immune cells, particularly mast cells and neutrophils (Oliani et al. 2001; Gil et al. 2006; Gavins and Hickey 2012). However, the relationship between ANXA1 and endometriosis is not well studied. One study described increased levels of ANXA1 protein and mRNA in the eutopic endometrium from patients with endometriosis without significant differences between proliferative and secretory phase (Li et al. 2008). Furthermore, in this study, ANXA1 was detected in the peritoneal fluids of patients, suggesting a role of this protein in the pathogenesis of endometriosis.

The anti-inflammatory effects of ANXA1 are mediated through formyl peptide receptors (FPR), a family of $G$ protein-coupled receptors (D'Acquisto et al. 2008; Dufton et al. 2010; Dufton and Perretti 2010). Only three FPR types have been described in humans including FPR1, FPR2/ALX (also known as FPRL-1) and FPR3 (formerly designated as FPRL-2) (Dufton and Perretti 2010). FPR expression occurs mainly in innate immune cells such as monocytes, macrophages, dendritic cells, neutrophils, hepatocytes and fibroblasts (Dufton and Perretti 2010). One study reported the expression of FPR2/ALX in epithelial and stromal cells in the human endometrium (Macdonald et al. 2011). This group showed using RT-PCR that receptor upregulation correlated with the menstrual phase of the endometrial cycle and first trimester of pregnancy, indicating a role of FPR2/ALX in endometrium physiology.

Considering the complex and multifactorial pathogenesis of endometriosis, in this study, we focus one type and specific localization of this disease (abdominal wall endometrioma) to evaluate the expression of mast cell proteases and ANXA1-FPR system and correlate their functions with the development of this pathology.

\section{Materials and methods}

\section{Patients}

The patients in this study were included using the following criteria: age between 20 and 45 years, regular menstrual cycles, absence of hormone therapy within 3 months prior to consultation, and absence of autoimmune diseases confirmed by history and laboratory tests, when necessary. The patients were divided into the following two groups: women with abdominal wall endometriosis $(n=18)$ and women without the disease (control $\mathrm{n}=10$ ).

From July 2003 to January 2012, eighteen biopsies of abdominal wall endometrioma (ectopic endometrium), which were confirmed by histology, were provided by the Department of Pathology and Forensic Medicine, São José do Rio Preto School of Medicine (FAMERP), Brazil.

For the control group, ten eutopic endometrium samples were collected by hysteroscopy from patients without endometriosis as determined by clinical and physical examination or ultrasound. The samples were collected between June 2011 and July 2012 in the Division of Human Reproduction, Department of Gynaecology and Obstetrics (FAMERP), Brazil. The surgical procedure was carried out after obtaining written informed consent.

All samples were in the proliferative phase of the menstrual cycle, between the 8th and 12th day, and processed for paraffin embedding.

\section{Ethical approval}

The study was approved by the Research and Ethics Committee of the São José do Rio Preto School of Medicine (FAMERP) (Protocol number 101/2011).

Histopathology and quantitative analysis

Eutopic $(\mathrm{n}=10)$ and ectopic $(\mathrm{n}=18)$ endometrium samples were fixed in $4 \%$ buffered formalin for $24 \mathrm{~h}$, washed in tap water, dehydrated in an ethanol series, and embedded in paraffin. Histopathology and quantitative analysis of inflammatory cells were performed on 4- $\mu \mathrm{m}$ sections of samples that were stained with haematoxylineosin and $0.5 \%$ toluidine blue. Histological analysis of the ectopic tissues was performed using specific morphological classifications (Abrao et al. 2003). In brief, the biopsies were classified as pure stromal, well-differentiated, undifferentiated, or mixed glandular.

Mast cells (intact and degranulated) were evaluated in $4 \mu \mathrm{m}$ tissue sections by visual inspection in a blind fashion and counted with a $40 \times$ objective on an Axioskop 2-Mot Plus Zeiss microscope (Carl Zeiss, Jena, Germany). Twenty-seven random fields in the eutopic and ectopic tissues were analysed per patient, and the area was determinted using AxioVision software. The values are reported as the mean \pm standard error of the mean (SEM) of the number of cells per $\mathrm{mm}^{2}$. The same quantification method was used to analyse the number of tryptase and chymase positive mast cells. 
Immunohistochemical studies

\section{Mast cell tryptase and chymase expression}

To better understand the mast cell heterogeneity in the eutopic and ectopic endometria, the expression of tryptase and chymase proteases was investigated in $4 \mu \mathrm{m}$ sections of the paraffin embedded tissues. After an antigen retrieval step using citrate buffer $\left(\mathrm{pH}\right.$ 6.0) at $96{ }^{\circ} \mathrm{C}$ for $30 \mathrm{~min}$, endogenous peroxide activity was blocked and the sections were incubated overnight at $4{ }^{\circ} \mathrm{C}$ with the primary mouse monoclonal anti-chymase (1:100; Abcam, Cambridge, UK) and goat polyclonal anti-tryptase (1:200; Novocastra, UK) antibodies diluted in $2 \%$ BSA. After washing, the sections were incubated with a secondary biotinylated antibody (Dako, Cambridge, UK). Positive staining was detected colourimetrically using a peroxidase conjugated streptavidin complex and DAB substrate (Dako, Cambridge, UK). The sections were counterstained with haematoxylin.

Quantification of tryptase and chymase-positive mast cells was performed in serial sections for each sample as described above. The values are reported as the mean \pm SEM of number of the cells per $\mathrm{mm}^{2}$.

Densitometric analyses for the protease immunostaining were performed in twenty mast cells per patient $(n=10 /$ group). The values were obtained as arbitrary units (a.u.) between 0 and 255 using AxioVision software on a ZeissAxioskop II light microscope. The data are expressed as the mean \pm SEM.

\section{ANXA1 and FPR expression}

The detection of ANXA1 and FPR expression in the eutopic and ectopic tissues was performed according to a immunohistochemistry protocol using the primary rabbit polyclonal antibodies anti-ANXA1 (1:2,000) (Zymed Laboratories, Cambridge, UK), anti-FPR1 and anti-FPR2 (1:2,000 and 1:500, respectively; Abcam Cambridge, UK) diluted in $2 \%$ BSA.

Densitometric analyses for the ANXA1 and FPR immunostaining were performed in the epithelial glandular tissue from eutopic $(n=10)$ and ectopic $(n=18)$ endometrium. The data are expressed as the mean \pm SEM using arbitrary units (a.u.).

\section{Postembedding immunogold labelling}

To detect the co-localisation of endogenous ANXA1 protein with the FPR1 in epithelial cells, ultrathin Sections $(90 \mathrm{~nm})$ from eutopic and ectopic endometrium were incubated sequentially with the following reagents at room temperature: (i) distilled water; (ii) $0.1 \mathrm{~mol} / \mathrm{L}$ phosphate buffer containing $1 \%$ egg albumin (PBEA); (iii) $0.1 \mathrm{~mol} / \mathrm{L}$
PBS containing $5 \%$ egg albumin (PBEA) for $30 \mathrm{~min}$; (iv) the sheep polyclonal antibody LPCS1 raised against ANXA1 (1:200 in PBEA) and rabbit polyclonal antibody FPR1 (1:100 in PBEA) for $2 \mathrm{~h}$, with normal sheep and rabbit sera as controls (1:200); and (v) three washes (5 min each) in PBEA containing $0.01 \%$ Tween 20. To detect ANXA1, a donkey anti-sheep IgG (Fc fragment-specific) antibody (1:100 in PBEA) conjugated to 10-nm colloidal gold (British Biocell, Cardiff, UK) was added. To detect FPR1, a goat anti-rabbit IgG (Fc fragment-specific) antibody (1:100 in PBEA) conjugated to $15 \mathrm{~nm}$ colloidal gold (British Biocell, Cardiff, UK) was added. After $1 \mathrm{~h}$, the sections were washed extensively in PBEA containing $0.01 \%$ Tween 20 and then in distilled water. These sections were stained with uranyl acetate and lead citrate and then examined using a ZEISS EM900 electron microscope (Department of Morphology and Genetics, UNIFESP).

Statistical analysis

The data were analysed using GraphPad software version 4.00. Significant differences between two groups were determined using Student's $t$ test; more than two conditions were analysed by the Bonferroni test. In all cases, a probability value $<0.05$ was considered significant.

\section{Results}

Histopathological evaluation of eutopic and ectopic endometria

Histopathological analysis of the eutopic endometria from patients without endometriosis (control group; $\mathrm{n}=10$ ) revealed typical histological organisation of the mucosal layer of the uterus characterized by a simple columnar epithelium composed of nonciliated secretory columnar cells, ciliated cells, and a lamina propria (loose connective tissue) with straight tubular glands lined by columnar epithelium (Fig. 1a, b). This glandular pattern confirmed that the fragments were collected in the proliferative phase.

The ectopic lesions $(n=18)$ showed two morphological patterns of endometriosis according to the histology classification proposed by Abrao et al. (2003). The first was a glandular pattern of mixed differentiation $(\mathrm{n}=11)$ characterised by the presence of an epithelial component composed of both endometrial-like cells (single columnar epithelium/well-differentiated glands) and undifferentiated cells (simple squamous or cubic epithelium) in the same fragment (Fig. 1c, d). The second was an undifferentiated glandular pattern $(n=7)$ with the presence of epithelium forming glandular cystic spaces consisting of flattened or low cuboidal cells. These lesions contained a higher influx 


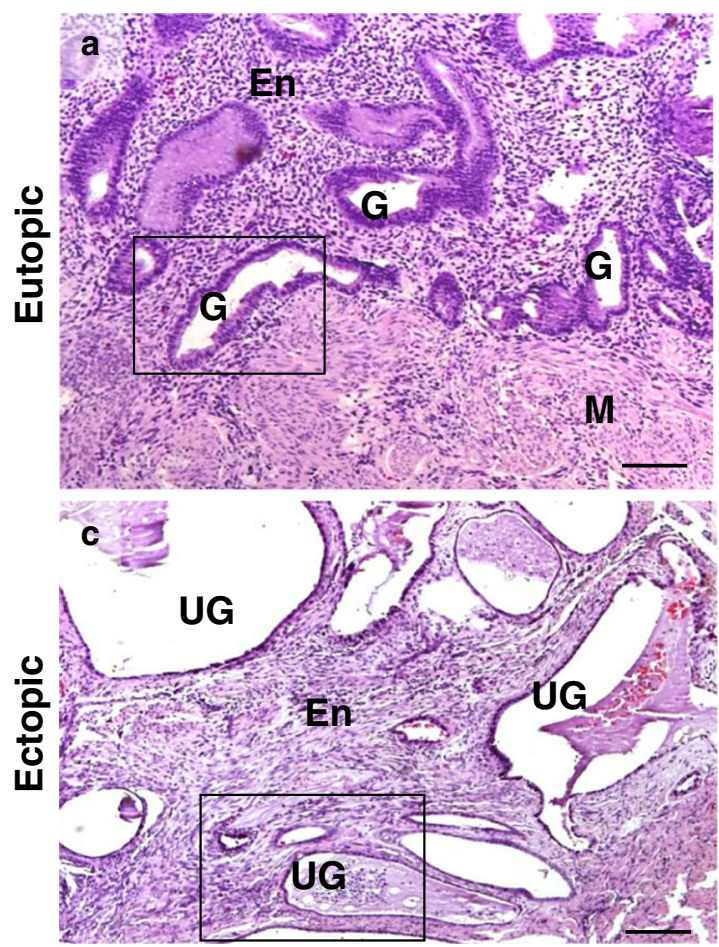

Fig. 1 Histological analysis of the eutopic and ectopic endometrium biopsies. a Uterine glands $(\mathrm{G})$ in the eutopic endometrium (En) in the proliferative phase. b Magnification of the squared area from Fig. 1a showing the uterine gland $(\mathrm{G})$ surrounded by the stroma (S). Myometrium (M). c Ectopic endometrium (En) with an

Table 1 Quantitative analysis of mast cells in the eutopic and ectopic endometria

\begin{tabular}{|c|c|c|c|}
\hline \multirow[t]{2}{*}{ Endometrium } & \multicolumn{3}{|l|}{ Mast Cells } \\
\hline & $\begin{array}{l}\text { Total } \\
\left(\text { cells } / \mathrm{mm}^{2}\right)\end{array}$ & $\begin{array}{l}\text { Intact } \\
\left(\text { cells } / \mathrm{mm}^{2}\right)\end{array}$ & $\begin{array}{l}\text { Degranulated } \\
\left(\text { cells } / \mathrm{mm}^{2} \text { ) }\right.\end{array}$ \\
\hline Eutopic & $3.30 \pm 1.48$ & $3.30 \pm 1.48$ & $0 \pm 0$ \\
\hline Ectopic & $41.44 \pm 2.78 * * *$ & $34.11 \pm 2.30 * * *$ & $7.33 \pm 0.75^{*}$ \\
\hline
\end{tabular}

The data represent the mean \pm S.E.M. of the number of cells per $\mathrm{mm}^{2}$ observed in 27 fields of the endometrium biopsies per patient (eutopic, $\mathrm{n}=10$; ectopic, $\mathrm{n}=18$ )

$* P<0.05 ; * * * P<0.001$ versus eutopic (control)

of innate immune cells, especially lymphocytes, neutrophils and mast cells, in the stroma and lumen of undifferentiated glands (Fig. 1c, d) compared to the eutopic endometrium (Fig. 1a, b). These results indicate that an inflammatory process is associated with this pathology.

The mast cell population increases and displays changes in protease expression in the endometrioma

The mast cell population was analysed in the eutopic and ectopic samples by staining with toluidine blue to assess metachromasia in the cytoplasmic granules. A significant

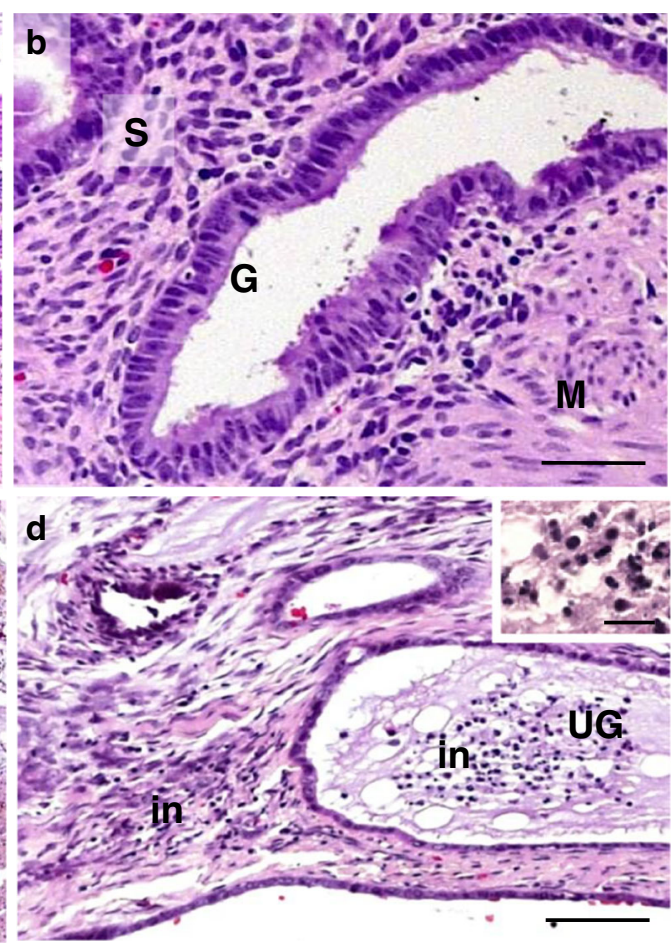

undifferentiated glandular (UG) pattern. d Inflammatory infiltrates (In) (inset) in the stroma and lumen of the undifferentiated gland with cubic epithelium (ep) (magnification of the squared area from Fig. 1c). Stain: Haematoxylin-eosin. Bars $100 \mu \mathrm{m}$ (a, c); $20 \mu \mathrm{m}(\mathbf{b}$, d); $5 \mu \mathrm{m}$ (inset)

increase in the number of metachromatic mast cells in the ectopic endometria was observed compared to the eutopic samples (Table 1). In addition, morphological study of the mast cells revealed a significant increase in the intact and degranulated cells in the ectopic samples compared to the control group (Table 1).

The increased number of mast cells in the ectopic lesions prompted us to investigate whether there was a change in mast cell heterogeneity. To do this, we evaluated chymase and tryptase expression. Immunohistochemical staining revealed that the eutopic and ectopic endometria contained tryptase- and chymase-positive cells located in the stroma and next to the endometrial glands (Fig. 2a-d). An analysis of serial and subsequent sections of the eutopic endometrium demonstrated high numbers of tryptasepositive cells compared to chymase-positive cells (Fig. 2a, b), whereas in the ectopic tissues, this predominance was not evident (Fig. 2d, e). This morphological observation was confirmed by measuring the density of the mast cells (Fig. 2c). There was a significant increase in chymasepositive cells in the ectopic endometrium compared to eutopic, but no difference was found in the tryptase-positive cell population (Fig. 2c).

Densitometric analysis of the mast cell proteases revealed no differences in tryptase levels in the 

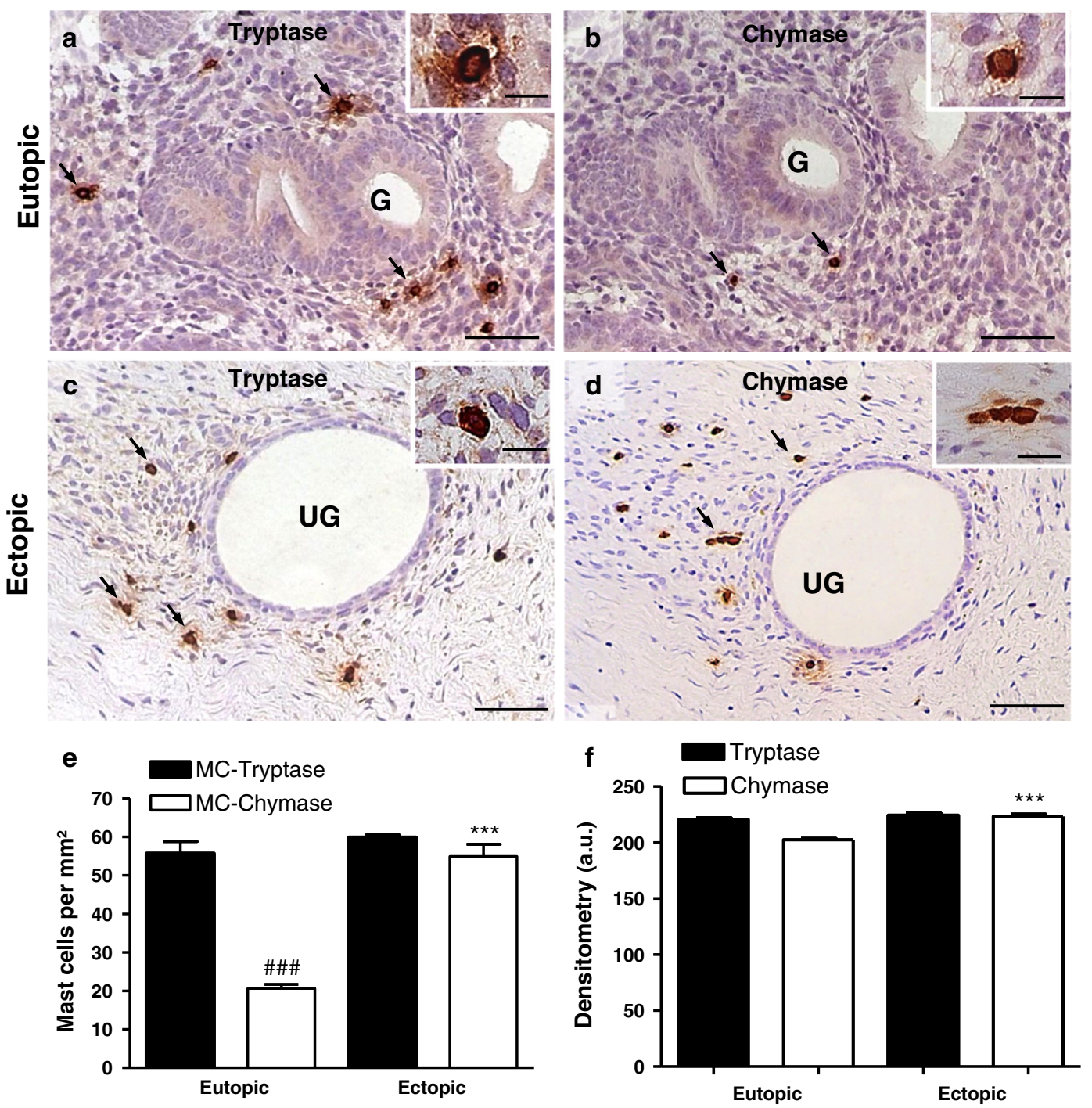

Fig. 2 Heterogeneity of the mast cells in the eutopic and ectopic endometria. Tryptase (a, c) and chymase-positive (b, d) mast cells (arrows) in close vicinity to the normal $(\mathrm{G})$ and undifferentiated (UG) uterine glands in subsequent histological sections of eutopic $(\mathbf{a}, \mathbf{b})$ and ectopic (c, d) endometria. An increase in chymase-positive cells was associated with the development of ectopic lesions (d). Counterstain: Hematoxylin. Bars $50 \mu \mathrm{m}$ (a-d), $10 \mu \mathrm{m}$ (details of a-d). e Quantitative analysis of tryptase- and chymase-positive mast cells. The data

cytoplasmic granules of the cells in the eutopic and ectopic endometria (Fig. 2f). On the other hand, the expression of chymase was significantly higher in the mast cells from the ectopic lesions compared to the cells from the eutopic lesions (Fig. 2f).

The expression of ANXA1-FPR1 system is upregulated in endometrioma

Because we found that endometrioma was associated with an increased mast cell population with changing heterogeneity, we next investigated the expression pattern of

represent the mean \pm S.E.M. of the number of cells per $\mathrm{mm}^{2}$ observed in 27 fields of the endometrium biopsies per patient (n=10/group). \#\# $P<0.001$ versus MC-tryptase (eutopic); $* * * P<0.001$ versus MC-Chymase (eutopic). f Densitometric analysis of tryptase and chymase expression in the cytoplasmic granules in mast cells. The data (arbitrary units) are expressed as the mean \pm SEM of 20 cells analysed per patient $(\mathrm{n}=10$ patients/ group). $* * * P<0.001$ versus chymase (eutopic)

ANXA1, a potent anti-inflammatory protein that is expressed in mast cells (Oliani et al. 2000; Polli-Lopes et al. 2013). In the eutopic and ectopic samples, ANXA1 immunostaining was detected in the epithelial cells, with intense immunoreactivity in ciliated, endothelial and stromal cells and neutrophils (Fig. 3a, b). Mast cells in the endometrium were also positive for ANXA1 (Fig. 3c, d), and this was confirmed by analysing serial sections of biopsies stained with toluidine blue (Fig. 3e, f).

In addition, to better understand ANXA1-FPR system in endometrium we performed immunohistochemical staining for FPR1 and FPR2. The eutopic and ectopic endometria 

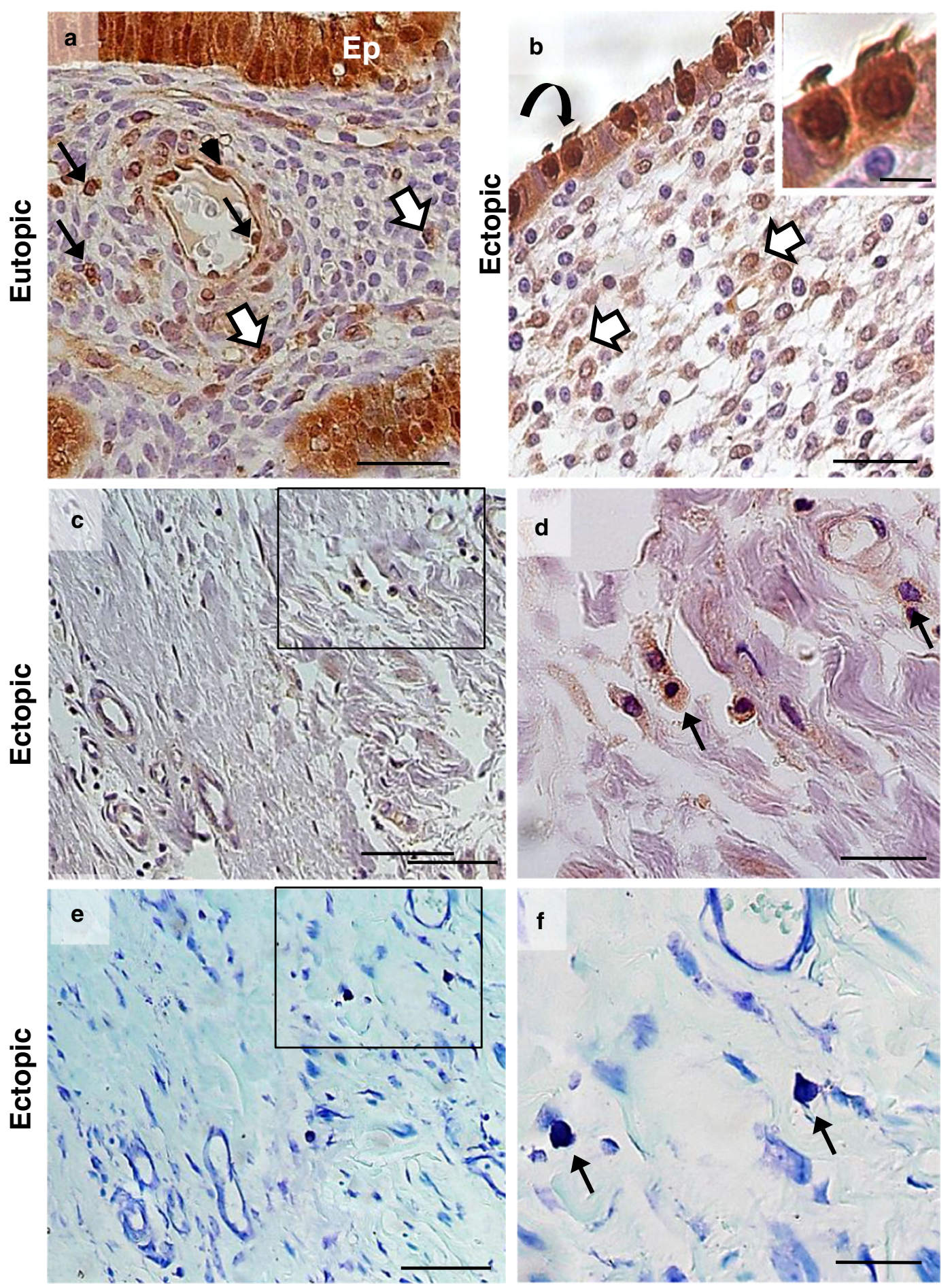

Fig. 3 Expression of ANXA1 protein in the endometrium. Epithelial glands (Ep), endothelial cells (arrowhead), stromal cells (white arrows) and neutrophils (black arrows) were positive for ANXA1 immunostaining in the eutopic (a) and ectopic (b) endometria. Higher levels of ANXA1 were detected in the ciliated epithelial cells (curved arrow; inset) compared to non-ciliated. c ANXA1-positive mast cells

displayed positive immunoreactivity for FPR1 and similar patterns of ANXA1 localisation. FPR1 was detected in endothelial, stromal and inflammatory cells, particularly (arrows) in the ectopic tissue. d Magnification of the squared area of (c) panel. Counterstain: Haematoxylin. e Histological section from panel (c) stained with $0.5 \%$ toluidine blue confirms that the ANXA1positive cells are mast cells (arrows). f Magnification of the squared area of (e) panel. Bars $20 \mu \mathrm{m}(\mathbf{a}, \mathbf{b}, \mathbf{d}$ and $\mathbf{f}) ; 50 \mu \mathrm{m}(\mathbf{c})$ and $(\mathbf{e}) ; 5 \mu \mathrm{m}$ (inset)

neutrophils, and in epithelial gland cells (data not shown). FPR2 expression was weak in both types of endometrial. For this reason, further analyses were performed only for FPR1. 

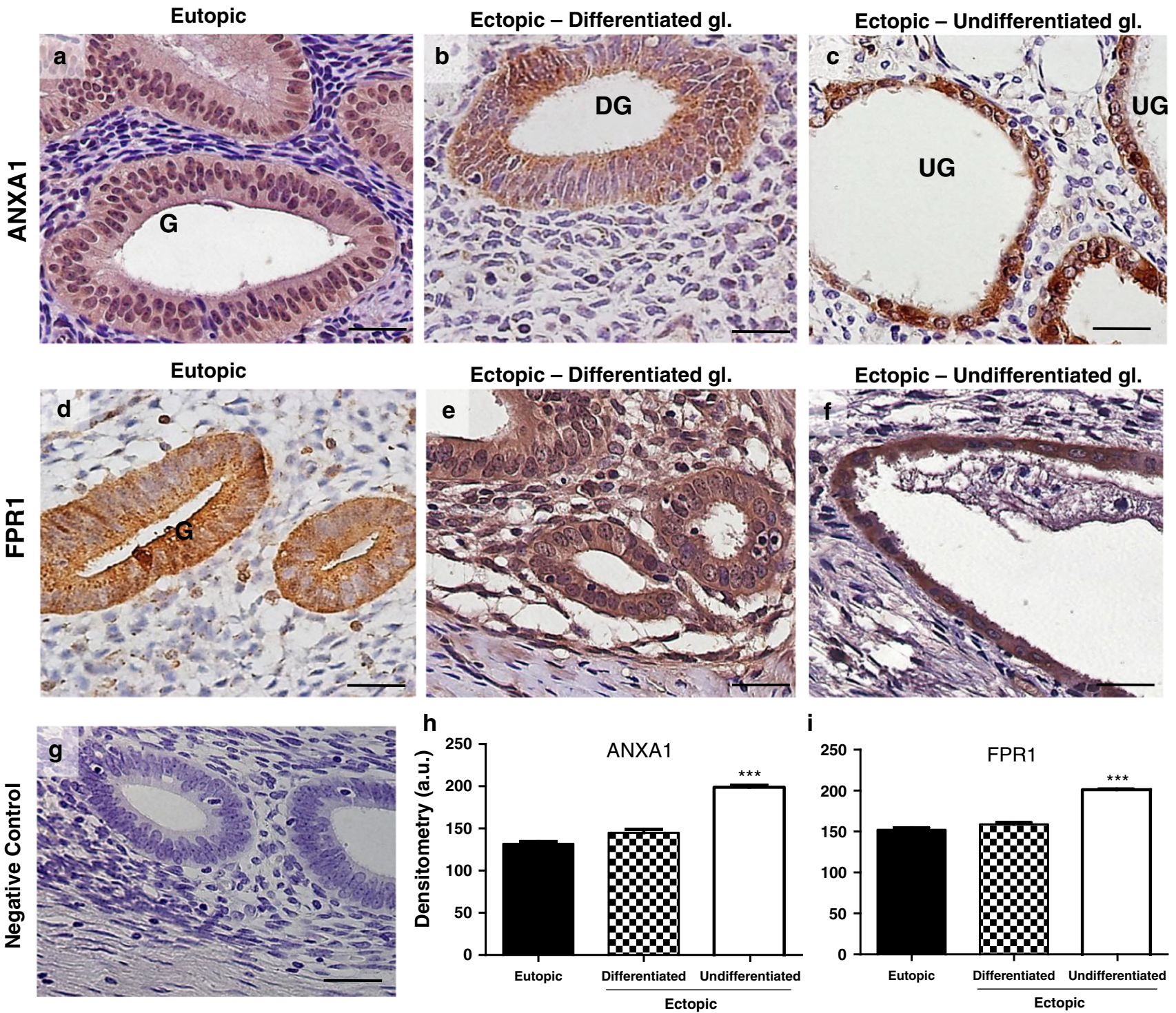

Fig. 4 ANXA1 and FPR1 immunostaining in the epithelial glands. Similar expression of ANXA1 (a) and FPR1 (d) are detected in the normal epithelial gland (G) from the eutopic endometrium and differentiated gland (DG) from the ectopic tissue (b and d, respectively). Strong ANXA1 (c) and FPR1 (f) immunostaining in undifferentiated epithelial glands (UG) from the ectopic fragments compared to normal (eutopic) and differentiated (ectopic) glands.

To directly evaluate the relationship between ANXA1FPR1 system expression and the change in the glandular pattern of endometriosis, we performed immunohistochemistry and ultrastructural immunocytochemistry. The epithelial gland cells from the eutopic and ectopic welldifferentiated glands showed similar patterns of ANXA1 (Fig. 4a, b) and FPR1 (Fig. 4d, e) expression. In contrast, undifferentiated glands (ectopic) demonstrated high immunoreactivity for ANXA1 (Fig. 4c) and FPR1 (Fig. 4f) compared to the eutopic and ectopic well-differentiated
(G) Absence of immunostaining in the control section. Counterstain: Haematoxylin. Bars $20 \mu \mathrm{m}$. Densitometric analysis of ANXA1 (h) and FPR1 (i) expression in the epithelial glands. The data (arbitrary units) are expressed as the mean \pm S.E.M. of the patient sections (eutopic, $\mathrm{n}=10$; ectopic, $\mathrm{n}=18$ ). ${ }^{* * *} P<0.001$ versus eutopic and differentiated glands (ectopic)

glands (Fig. 4a, b, d, e). There was no immunostaining in the endometrium used as a negative control (Fig. 4g). Densitometric analysis revealed a significant increase in the endogenous levels of ANXA1 (Fig. 4h) and FPR1 (Fig. 4i) expression in the undifferentiated glands compared to the eutopic and ectopic well-differentiated glands, confirming the morphological observations.

Ultrastructural analysis showed a similar pattern of ANXA1 and FPR1 expression in the epithelial gland cells of eutopic and ectopic samples. The expression was 

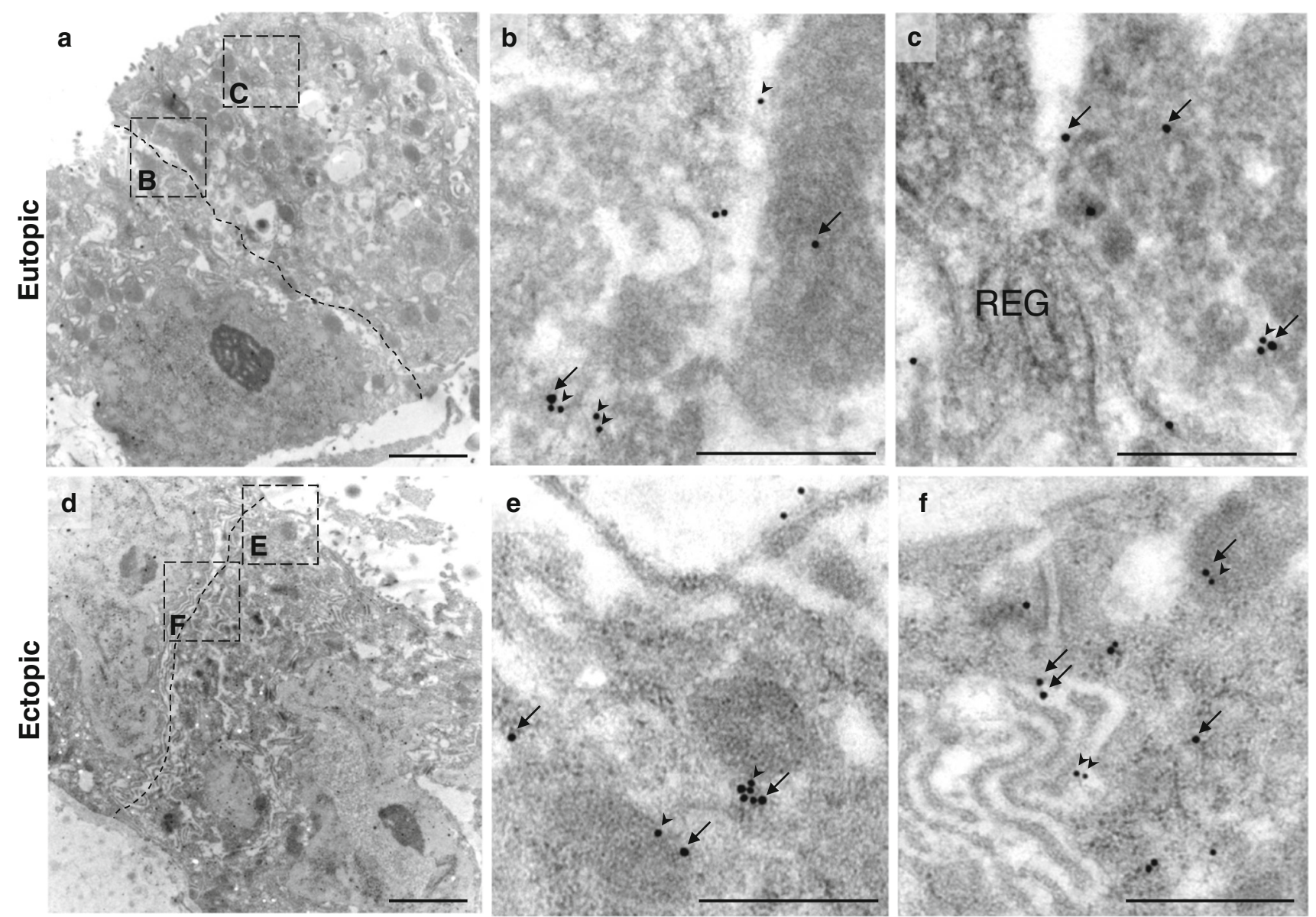

Fig. 5 Ultrastructural co-localisation of ANXA1 and FPR1 immunogold particles in the epithelial gland cells from the eutopic (a-c) and ectopic (d-f) endometria. a, d Panoramic electron micrograph of simple columnar epithelium with interdigitated lateral cell borders

localised in the cytoplasm and plasma membrane, with some points of co-localisation (Fig. 5).

\section{Discussion}

In the present study, we report a morphological alteration in the endometriotic lesions from abdominal wall endometrioma associated with inflammatory response characterized by increased inflammatory cell influx. The development of lesions was associated with a change in mast cell heterogeneity, as well as a marked increase in the endogenous levels of chymase. In addition, the undifferentiated glandular pattern of endometriotic lesions was positively associated with a marked increase and colocalization of ANXA1 and FPR1 in the epithelial cells.

In our study, histological analysis of 18 ectopic endometrium biopsies revealed two morphological glandular patterns: undifferentiated and mixed, indicating abdominal (dashed). ANXA1 (arrowheads) and FPR1 (arrows) co-localised in the plasma membrane and cytoplasm of eutopic (b, c) and ectopic (e, f) epithelial cells highlighted in the squared areas from panels (a) and (d). Bars $2 \mu \mathrm{m}(\mathbf{a}, \mathbf{d}) ; 0.5 \mu \mathrm{m}(\mathbf{b}, \mathbf{c}, \mathbf{e}$ and $\mathbf{f})$

wall endometrioma in the most advanced stage of endometriosis according previous study (Abrao et al. 2003). Another investigation analysing 271 biopsies from 176 patients indicated a predominance of undifferentiated and mixed glandular patterns in deep endometriosis biopsies (33.5 and $46.9 \%$, respectively) and endometrioma (40.5 and $37.8 \%$ ), while the differentiated glandular pattern (41, $8 \%$ ) was common in superficial endometriotic lesions. These results suggest a correlation between the undifferentiated glandular pattern and severity of disease (Kamergorodsky et al. 2009).

Quantitative analysis of the mast cells revealed an increased number of intact and degranulated cells in the ectopic endometrium compared to the eutopic (control). These cells were localised near the glands and blood vessels in the ectopic endometrium stroma and generally degranulated. Consistent with our study, degranulated mast cells have also been reported in other studies of endometriosis (Kempuraj et al. 2004; Fujiwara et al. 2004; 
Sugamata et al. 2005). In addition, in a study using an experimental model of endometriosis, rats treated with an antagonist of the leukotriene receptor showed a significant inhibition of infiltration and activation of mast cells in the endometrial lesions (Ihara et al. 2004). Lesions of deeply infiltrating endometriosis and generally associated with pelvic pain and exhibit a high number of activated mast cells next to the peripheral nerves compared to observations in peritoneal and ovarian endometriosis (Anaf et al. 2006). These data suggest a role of mast cells in the development of fibrosis, adhesion processes of endometriosis and the production of pain.

In this scenario, we evaluated the expression of tryptase and chymase in mast cells from eutopic and ectopic endometria to investigate mast cell heterogeneity. Quantitative analysis revealed that in eutopic samples, there was a predominance of tryptase-positive mast cells $\left(\mathrm{MC}_{\mathrm{T}}\right)$ compared to the chymase-positive subpopulation. These results are in agreement with studies that detected a predominance of the $\mathrm{MC}_{\mathrm{T}}$ subpopulation in the functional layer of the endometrium in 107 eutopic endometrium biopsies from women without endometriosis or leiomyoma and who did not have hormone treatment for 1 year (Jeziorska et al. 1995). On the other hand, there was a significant increase in chymase-positive cells in the ectopic endometria compared to the eutopic endometria, suggesting a change in the pattern of mast cell subtypes that are associated with lesions. Densitometric analysis revealed increased endogenous level of chymase, but not tryptase, in the cytoplasmic granules of mast cells from the ectopic endometrium. Similar results were reported in a study involving five types of endometriosis (peritoneal, ovarian, uterosacral ligaments, utero-vaginal septum, and bowel), which showed a significant increase in the chymase-positive mast cell subpopulation (Anaf et al. 2006). This same study showed elevated numbers of tryptase-positive mast cells in the lesions, except in ectopic tissues localised in the peritoneum and uterosacral ligament, compared to the tissues from regions not affected by endometriosis (controls). These data suggest that changes in the heterogeneity of mast cells are dependent on the type and localisation of endometriosis.

Because chymase is the first protease expressed in mast cells during maturation (Ma et al. 2008; Pejler et al. 2010), the detection of high numbers of chymase-positive cells indicates a predominance of immature cells in the different types of endometriosis. In addition to tryptase and chymase proteases, mast cells also express ANXA1, a potent antiinflammatory protein, which has not been well studied in the endometriosis. This finding corroborates the literature (Oliani et al. 2000; Gil et al. 2006; Sena et al. 2006; PolliLopes et al. 2013) and reveals mast cells as important sources of ANXA1 in the tissue.
Our immunohistochemical studies further detected ANXA1 in stromal and epithelial gland cells, with high immunoreactivity in the ciliated epithelial cells of the uterine mucosa in both the eutopic and ectopic samples. These results are similar to proteomic studies performed by western blotting and immunohistochemistry, which revealed ANXA1 as a component of the ciliary axoneme in human (Rodrigo Tapia et al. 2004; Ostrowski et al. 2002), bovine (Vishwanatha et al. 1995) and rabbit (Mayran et al. 1996) epithelial cells from the respiratory mucosa. In the female genital system, high expression of ANXA1 was detected in the placenta, ovaries, and uterus of pregnant rabbits compared to organs in the nonpregnant phase (Tsao et al. 1995). In the human uterine mucosa, RT-PCR and western blotting analysis indicated that ANXA1 mRNA and endogenous protein levels were not affected by the menstrual cycle but were elevated in the eutopic endometrium of patients with endometriosis compared to patients without the disease ( $\mathrm{Li}$ et al. 2008).

Our immunohistochemical and densitometric analyses detected increased ANXA1 expression in undifferentiated epithelial glands in the ectopic samples compared to the endometrial glands (control-eutopic) and differentiated glands in the ectopic endometrium. This difference was also reported in the eutopic endometrium from patients with stages II-IV endometriosis (according to ASRM). The endometrial from these patients also displayed high immunoreactivity for ANXA1 in the epithelial gland cells compared to the eutopic endometrium from patients without endometriosis ( $\mathrm{Li}$ et al. 2008). Most studies indicate a proliferative role for endogenous ANXA1 in epithelial cells (Mulla et al. 2004); (Bai et al. 2004) that activates the mitosis cascade through cyclin D1 using the FPR1 and FPR2 receptors (Khau et al. 2011).

Based on these data and the fact that few studies have investigated the expression of FPRs in the human endometrium, the next step of our study was to correlate the ANXA1 and FPR with the development of endometrioma. Immunohistochemical and ultrastructural immunogold labelling analysis demonstrated for the first time in the human endometrium that FPR1 expression occurred in the same regions as ANXA1 expression. The eutopic and ectopic endometrial had similar immunoreactivity to FPR1, particularly in the inflammatory, stromal and endothelial cells. However, a significant increase in receptor and ANXA1 expression occurred in the undifferentiated glands from the ectopic endometrium compared to the other gland patterns (normal-eutopic; well-differentiated-ectopic).

In summary, our results show that abdominal wall endometrioma exhibits changes in both the stroma and epithelium tissue compartments. Inflammatory cell influx and changes in mast cells that modulate the endogenous levels of chymase, a potent pro-inflammatory mediator, 
occur in the stroma. In the epithelium, the high levels of ANXA1 and FPR1 correlate with morphological alterations in this tissue, which may participate in cell differentiation and proliferation.

Acknowledgments This study was supported by FAPESP (2011/ 00128-1) and CNPq (302768/2010-6). R Paula Junior was supported by CAPES scholarship. The authors thank the resident students of Department of Gynaecology and Obstetrics, São José do Rio Preto School of Medicine (FAMERP) for their crucial help in eutopic endometrium sample collection.

Conflict of interest The authors have no competing financial interests to disclose in relation to this manuscript.

\section{References}

Abrao MS, Neme RM, Carvalho FM, Aldrighi JM, Pinotti JA (2003) Histological classification of endometriosis as a predictor of response to treatment. Int J Gynaecol Obstet 82(1):31-40

Accetta I, Accetta P, Accetta AF, Maia FJ, Oliveira AP (2011) Abdominal wall endometrioma. Rev Col Bras Cir 38(1):41-44

Anaf V, Chapron C, El Nakadi I, De Moor V, Simonart T, Noël JC (2006) Pain, mast cells, and nerves in peritoneal, ovarian, and deep infiltrating endometriosis. Fertil Steril 86(5):1336-1343. doi:10.1016/j.fertnstert.2006.03.057

Bai XF, Ni XG, Zhao P, Liu SM, Wang HX, Guo B, Zhou LP, Liu F, Zhang JS, Wang K, Xie YQ, Shao YF, Zhao XH (2004) Overexpression of annexin 1 in pancreatic cancer and its clinical significance. World J Gastroenterol 10(10):1466-1470

Burney RO (2013) The genetics and biochemistry of endometriosis. Curr Opin Obstet Gynecol 25(4):280-286. doi:10.1097/GCO. 0b013e3283630d56

D'Acquisto F, Perretti M, Flower RJ (2008) Annexin-A1: a pivotal regulator of the innate and adaptive immune systems. $\mathrm{Br} \mathrm{J}$ Pharmacol 155(2):152-169. doi:10.1038/bjp.2008.252

Ding Y, Zhu J (2013) A retrospective review of abdominal wall endometriosis in Shanghai. China. Int J Gynaecol Obstet 121(1):41-44. doi:10.1016/j.ijgo.2012.11.011

Dufton N, Perretti M (2010) Therapeutic anti-inflammatory potential of formyl-peptide receptor agonists. Pharmacol Ther 127(2): 175-188. doi:10.1016/j.pharmthera.2010.04.010

Dufton N, Hannon R, Brancaleone V, Dalli J, Patel HB, Gray M, D'Acquisto F, Buckingham JC, Perretti M, Flower RJ (2010) Anti-inflammatory role of the murine formyl-peptide receptor 2: ligand-specific effects on leukocyte responses and experimental inflammation. J Immunol 184(5):2611-2619. doi:10.4049/jimmu nol.0903526

Fujiwara H, Konno R, Netsu S, Sugamata M, Shibahara H, Ohwada M, Suzuki M (2004) Localization of mast cells in endometrial cysts. Am J Reprod Immunol 51(5):341-344. doi:10.1111/j. 1600-0897.2004.00166.x

Gavins FN, Hickey MJ (2012) Annexin A1 and the regulation of innate and adaptive immunity. Front Immunol 3:354. doi:10. 3389/fimmu.2012.00354

Gil C, La M, Perretti M, Oliani S (2006) Interaction of human neutrophils with endothelial cells regulates the expression of endogenous proteins annexin 1, galectin-1 and galectin-3. Cell Biol Int 30(4):338-344. doi:10.1016/j.cellbi.2005.12.010

Giudice LC, Kao LC (2004) Endometriosis. Lancet 364(9447):1789-1799. doi:10.1016/S0140-6736(04)17403-5

Ihara T, Uchiide I, Sugamata M (2004) Light and electron microscopic evaluation of antileukotriene therapy for experimental rat endometriosis. Fertil Steril 81(Suppl 1):819-823. doi:10.1016/j. fertnstert.2003.08.029

Jeziorska M, Salamonsen LA, Woolley DE (1995) Mast cell and eosinophil distribution and activation in human endometrium throughout the menstrual cycle. Biol Reprod 53(2):312-320

Jiang QY, Wu RJ (2012) Growth mechanisms of endometriotic cells in implanted places: a review. Gynecol Endocrinol 28(7):562-567. doi:10.3109/09513590.2011.650662

Kamergorodsky G, Ribeiro PA, Galvão MA, Abrão MS, Donadio N, Lemos NL, Aoki T (2009) Histologic classification of specimens from women affected by superficial endometriosis, deeply infiltrating endometriosis, and ovarian endometriomas. Fertil Steril 92(6):2074-2077. doi:10.1016/j.fertnstert.2009.05. 086

Kempuraj D, Papadopoulou N, Stanford EJ, Christodoulou S, Madhappan B, Sant GR, Solage K, Adams T, Theoharides TC (2004) Increased numbers of activated mast cells in endometriosis lesions positive for corticotropin-releasing hormone and urocortin. Am J Reprod Immunol 52(4):267-275. doi:10.1111/j. 1600-0897.2004.00224.x

Khau T, Langenbach SY, Schuliga M, Harris T, Johnstone CN, Anderson RL, Stewart AG (2011) Annexin-1 signals mitogenstimulated breast tumor cell proliferation by activation of the formyl peptide receptors (FPRs) 1 and 2. FASEB J 25(2):483-496. doi:10.1096/fj.09-154096

Konno R, Yamada-Okabe H, Fujiwara H, Uchiide I, Shibahara H, Ohwada M, Ihara T, Sugamata M, Suzuki M (2003) Role of immunoreactions and mast cells in pathogenesis of human endometriosis-morphologic study and gene expression analysis. Hum Cell 16(3):141-149

Li CY, Lang JH, Liu HY, Zhou HM (2008) Expression of Annexin-1 in patients with endometriosis. Chin Med J (Engl) 121(10):927-931

Ma F, Kambe N, Wang D, Shinoda G, Fujino H, Umeda K, Fujisawa A, Ma L, Suemori H, Nakatsuji N, Miyachi Y, Torii R, Tsuji K, Heike T, Nakahata T (2008) Direct development of functionally mature tryptase/chymase double-positive connective tissue-type mast cells from primate embryonic stem cells. Stem Cells 26(3):706-714. doi:10.1634/stemcells.2007-0348

Macdonald LJ, Boddy SC, Denison FC, Sales KJ, Jabbour HN (2011) A role for lipoxin A4 as an anti-inflammatory mediator in the human endometrium. Reproduction 142(2):345-352. doi:10. 1530/REP-11-0021

Mayran N, Traverso V, Maroux S, Massey-Harroche D (1996) Cellular and subcellular localizations of annexins I, IV, and VI in lung epithelia. Am J Physiol 270(5 Pt 1):L863-L871

Menzies FM, Shepherd MC, Nibbs RJ, Nelson SM (2011) The role of mast cells and their mediators in reproduction, pregnancy and labour. Hum Reprod Update 17(3):383-396. doi:10.1093/ humupd/dmq053

Mulla A, Christian HC, Solito E, Mendoza N, Morris JF, Buckingham JC (2004) Expression, subcellular localization and phosphorylation status of annexins 1 and 5 in human pituitary adenomas and a growth hormone-secreting carcinoma. Clin Endocrinol (Oxf) 60(1):107-119

Oliani SM, Christian HC, Manston J, Flower RJ, Perretti M (2000) An immunocytochemical and in situ hybridization analysis of annexin 1 expression in rat mast cells: modulation by inflammation and dexamethasone. Lab Invest 80(9):1429-1438

Oliani SM, Paul-Clark MJ, Christian HC, Flower RJ, Perretti M (2001) Neutrophil interaction with inflamed postcapillary venule endothelium alters annexin 1 expression. Am $\mathbf{J}$ Pathol 158(2):603-615

Ostrowski LE, Blackburn K, Radde KM, Moyer MB, Schlatzer DM, Moseley A, Boucher RC (2002) A proteomic analysis of human cilia: identification of novel components. Mol Cell Proteomics 1(6):451-465 
Ozel L, Sagiroglu J, Unal A, Unal E, Gunes P, Baskent E, Aka N, Titiz MI, Tufekci EC (2012) Abdominal wall endometriosis in the cesarean section surgical scar: a potential diagnostic pitfall. J Obstet Gynaecol Res 38(3):526-530. doi:10.1111/j.1447-0756. 2011.01739.x

Pejler G, Rönnberg E, Waern I, Wernersson S (2010) Mast cell proteases: multifaceted regulators of inflammatory disease. Blood 115(24):4981-4990. doi:10.1182/blood-2010-01-257287

Podgaec S, Abrao MS, Dias JA, Rizzo LV, de Oliveira RM, Baracat EC (2007) Endometriosis: an inflammatory disease with a Th2 immune response component. Hum Reprod 22(5):1373-1379. doi:10.1093/humrep/del516

Polli-Lopes AC, Estofolete CF, Oliani SM, Zucoloto S, Cunha FQ, Gil CD (2013) Myenteric denervation in gastric carcinogenesis: differential modulation of nitric oxide and annexin-A1. Int J Clin Exp Pathol 6(1):13-23

Rodrigo Tapia JP, García Pedrero JM, Pena Alonso E, Fernández MP, Morgan RO, Suárez Nieto C, Herrero Zapatero A (2004)
Expression of annexins $\mathrm{Al}$ and $\mathrm{A} 2$ in the mucosa of the upper airdigestive tract. Acta Otorrinolaringol Esp 55(7):310-314

Sena AA, Provazzi PJ, Fernandes AM, Cury PM, Rahal P, Oliani SM (2006) Spatial expression of two anti-inflammatory mediators, annexin 1 and galectin-1, in nasal polyposis. Clin Exp Allergy 36(10):1260-1267. doi:10.1111/j.1365-2222.2006.02570.x

Sugamata M, Ihara T, Uchiide I (2005) Increase of activated mast cells in human endometriosis. Am $\mathrm{J}$ Reprod Immunol 53(3):120-125. doi:10.1111/j.1600-0897.2005.00254.x

Tsao FH, Chen X, Ts'ao CH (1995) Annexin I in female rabbit reproductive organs: varying levels in relation to maturity and pregnancy. Lipids 30(6):507-511

Vishwanatha JK, Muns G, Beckmann JD, Davis RG, Rubinstein I (1995) Differential expression of annexins I and II in bovine bronchial epithelial cells. Am J Respir Cell Mol Biol 12(3):280-286. doi:10.1165/ajrcmb.12.3.7873194 